\title{
New strategy for reducing the EHL friction in steel contacts using additive-formed oleophobic boundary films
}

\author{
Mitjan KALIN*, Maja KUS \\ Laboratory for Tribology and Interface Nanotechnology, Faculty of Mechanical Engineering, University of Ljubljana, \\ Bogišićeva 8, 1000 Ljubljana, Slovenia \\ Received: 06 April 2020 / Accepted: 15 May 2020 \\ (C) The author(s) 2020 .
}

\begin{abstract}
In this study we present a mechanism for the elastohydrodynamic (EHD) friction reduction in steel/steel contacts, which occurs due to the formation of oleophobic surface boundary layers from common boundary-lubrication additives. Several simple organic additives (amine, alcohol, amide, and fatty acid) with different molecular structures were employed as the model additives. It was found that the stronger chemisorption at $100{ }^{\circ} \mathrm{C}$, rather than the physisorption at $25{ }^{\circ} \mathrm{C}$, is more effective in friction reduction, which reaches $22 \%$. What is more, EHD friction reduction was obtained in steel/steel contacts without use of the diamond-like carbon (DLC) coatings with their wetting or thermal effect, which was previously suggested as possible EHD friction reduction mechanism; yet about the same friction reduction of about $20 \%$ was obtained here-but with much simpler and less expensive technology, namely with the adsorbed oleophobic surface layers. A small variation in the additive's molecular structure results in significant changes to the friction, indicating good potential in future EHD lubrication technology, where these additives could be designed and well optimised for notable reduction of the friction losses in the EHD regime.
\end{abstract}

Keywords: elastohydrodynamic (EHD); friction; additives; oleophobic layer; boundary slip

\section{Introduction}

In engineering applications many lubricated contacts correspond to conditions of elasto-hydrodynamic (EHD) or hydrodynamic (HD) lubrication regime [1-3]. These are the most desirable lubrication regimes for both friction and wear. In these full-film conditions, film pressure is able to resist the load and separate the contacts, preventing any severe collisions between the surface asperities that enhance the friction and wear. Accordingly, in the HD and EHD full-film regimes, the viscous friction dominates the contact, rather than the solid-solid asperities.

Until now, for the vast majority of engineering applications and engineering HD/EHD lubrication models, the viscosity was considered to be the main parameter of the oil that governs the lubrication [1]. Viscosity changes with the pressure and temperature are critical influences in that respect, since they define the actual thickness of the lubricating film. However, recently, the contacting materials also became of interest for EHD lubrication, in at least two different ways. One of the two suggestions is that higher thermal insulation surfaces (compared to steel), such as diamond-like carbon (DLC), might generate higher surface temperatures, affecting the oil temperature in the contact and so reducing the oil's viscosity, which then affects the EHD friction [4].

Another suggestion for reducing the EHD friction

* Corresponding author: Mitjan KALIN, E-mail: mitjan.kalin@tint.fs.uni-lj.si 
that goes beyond the viscosity effects is focusing on the boundary-layer effects at the solid-liquid interaction [5-9]. In several studies with a systematic variation of the DLC coatings' surface-energy values and consequently the wetting behaviours with base oils [10], it was found that a significant and consistent EHD friction reduction, even up to $50 \%$ [6, 7], can be achieved. These and other EHD studies pointed out the importance of the surface energy (mainly the polar component) $[6,7,10,11]$, the wetting $[10$, 11], and in particular the spreading [10], which can affect the boundary slip of the lubricant over the surface and so reduce the friction drag in conditions of full-film lubrication. The effect of low wetting, as well as boundary slip, on the friction, drag or energy losses reduction was previously proposed on many occasions in nano-scale studies [12-15] or theoretically [16-18], as well as for low-load HD contacts in the MPa contact-pressure range $[8,19,20]$.

However, within the EHD contacts, where the contact pressure can reach a few GPa, several other critical physical phenomena occur simultaneously, in particular temperature increases and dramatic viscosity changes, but their true values and effects are not easy to experientially verify. As such, disagreements for the theoretical models that rely on temperature or viscosity still exist. Accordingly, establishing wetting and boundary-slip effects in EHD lubrication-a very new phenomenon in EHD lubrication-in addition to the above-mentioned parameters that have dominated for a century, is a challenging task. This is because the effects and the individual contributions of pressure, temperature, and wetting are difficult to isolate.

The above consideration regarding wetting influence on the friction in contacts with DLC coatings possessing low-surface-energy, one may suggest that the same should occur if the surface wetting is modified with the adsorbed additive layers, such as used in conventional boundary lubrication, if these layers could provide low surface energy, once adsorbed at the surface. So far, the studies of effect of additives on the wetting performance, and even more, of their effect with temperature variation are almost completely absent. However, if we could achieve that additives are used on, for example bare steel surfaces, making them oleophobic, with low wetting behaviour that will facilitate slip and so reduce full-film friction, this would be of great importance and advantage over employing the DLC coatings, which are more expensive and more difficult to deposit, especially to complex geometries and higher roughness engineering components.

In fact, our very recent studies on the effect of additives (simple organic friction modifiers) on the oil-steel wetting show a notable rise in the oleophobic properties of steel surface due to additive adsorption, both at $25{ }^{\circ} \mathrm{C}$ due to physisorption [21] and at $100{ }^{\circ} \mathrm{C}$ due to chemisorption [22]. Moreover, relevant molecular structure effects, such as the number of polar groups, chain length, polarity and saturation, were identified in these studies. Accordingly, in this study we analyse how these, the same simple organic friction modifiers, as used in [21, 22] and with the same variation of their molecular structures, affect the friction in EHD steel-on-steel contacts at room temperature of $25{ }^{\circ} \mathrm{C}$ and also at increased temperature of $100{ }^{\circ} \mathrm{C}$. Moreover, the adsorption of the additives is analysed via attenuated total reflectance Fourier-transform infrared spectroscopy (ATR-FTIR) to explain and support the friction results.

\section{Experimental}

\subsection{Materials and lubricants}

In this work we used specimens from a MTM tribology tester (PCS Instruments, London, UK), which is described later on, namely discs and balls from steel DIN 100Cr6/AISI52100. Discs have a $46 \mathrm{~mm}$ diameter, while balls $19.05 \mathrm{~mm}$. Both the balls and the discs were hardened to about 760 Vickers, as reported by producer. The used samples were very smooth, as reported by producer and confirmed with a white light interferometer (Contour, GT-K0, Bruker, USA), Table 1. Moreover, we also checked that the roughness values of the samples did not

Table 1 Roughness values of the samples for tribological MTM tests.

\begin{tabular}{ccc}
\hline Sample & $R_{a}(\mu \mathrm{m})$ & $R_{q}(\mu \mathrm{m})$ \\
\hline Ball & $0.014 \pm 0.003$ & $0.018 \pm 0.004$ \\
Disc & $0.012 \pm 0.003$ & $0.015 \pm 0.004$ \\
\hline
\end{tabular}


change during the tests, confirming that the tests were indeed in full-film regime.

For the investigation of the influence of additives at two distinct temperatures, 25 and $100{ }^{\circ} \mathrm{C}$, we selected two base oils to have the same kinematic viscosity at the selected temperatures, i.e., $62.5 \pm 0.3$ $\mathrm{mm}^{2} / \mathrm{s}$. Accordingly, the selected oils were polyalpha-olefin base oils (PAO), with the same chemical structure, but two different viscosity grades, i.e., PAO 6 and PAO 65 (Total, Solaize, France), and are the same, as used in companion study in Refs. [21, 22]. Their key physical properties are given in Table 2 . Tribotests were performed with the base PAO and a PAO with $4 \mathrm{wt} \%$ of the selected additive to ensure the additive effect. The same concentration was also used in earlier studies and was defined based on its applicability to some real engineering cases [23-25].

A number of simple additives with polar head groups were used in this study to analyse the effect of some fundamental additive variations [26-29] on the friction in EHD contacts. As mentioned earlier, these molecules are exactly the same as used in earlier companion wetting studies [21, 22], where more details can also be found. A summary of the molecules used and their variation is presented in Fig. 1.

Table 2 Kinematic viscosity, surface tension, and density of selected base oils.

\begin{tabular}{lcc}
\hline Oil & PAO 6 & PAO 65 \\
\hline Kinematic viscosity at $25{ }^{\circ} \mathrm{C}\left(\mathrm{mm}^{2} / \mathrm{s}\right)$ & 62.28 & $1,340.93$ \\
Kinematic viscosity at $40{ }^{\circ} \mathrm{C}\left(\mathrm{mm}^{2} / \mathrm{s}\right)$ & 30.52 & 591.49 \\
Kinematic viscosity at $100{ }^{\circ} \mathrm{C}\left(\mathrm{mm}^{2} / \mathrm{s}\right)$ & 5.84 & 62.78 \\
Surface tension at $25{ }^{\circ} \mathrm{C}(\mathrm{mN} / \mathrm{m})$ & 29.07 & 30.41 \\
Surface tension at $100{ }^{\circ} \mathrm{C}(\mathrm{mN} / \mathrm{m})$ & 27.73 & 28.82 \\
Density at $25{ }^{\circ} \mathrm{C}\left(\mathrm{g} / \mathrm{cm}^{3}\right)$ & 0.822 & 0.837 \\
Density at $100{ }^{\circ} \mathrm{C}\left(\mathrm{g} / \mathrm{cm}^{3}\right)$ & 0.784 & 0.798 \\
\hline
\end{tabular}

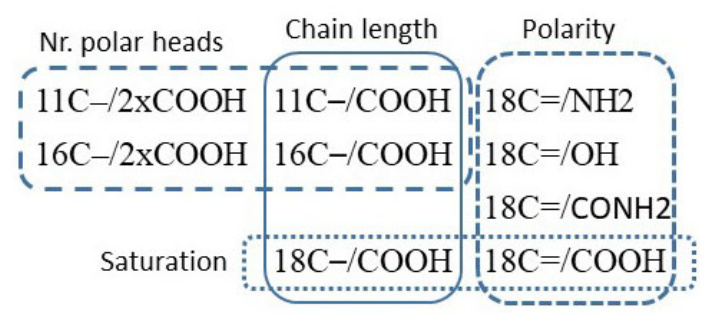

Fig. 1 Variation of nine additive molecules (undecanedioic, hexadecanedioic, undecanoic, palmitic, stearic and oleic acids, oley amine, oleyl alcohol, and oleylamide) indicating direct comparison of their properties.
In the nine different additive molecules we varied the length of alkyl chain of 11,16 , and $18 \mathrm{C}$ atoms, which is one of the most recognised additive effects $[28,29]$. The second important parameter is the polarity [26, 27], which was varied by selecting different functional groups: amine $\left(-\mathrm{NH}_{2}\right)$, which has the lowest polarity, hydroxide $(-\mathrm{OH})$ with higher polarity, but the lowest than amide (-CO $\left.-\mathrm{NH}_{2}\right)$, and finally, carboxyl $(-\mathrm{COOH})$ group with the highest polarity [27]. The polarity variation was made with molecules that all have double bond $(C=C)$, because of their better solubility than those with single $(C-C)$ bonds. Finally, saturation effect was also investigated. Four unsaturated and five saturated molecules were used, but for direct comparison, we used molecules with one carboxylic $(\mathrm{COOH})$ group with alkyl chain length of $18 \mathrm{C}$ atoms, but having all single or one double bond.

The mixtures of PAO oil and additive were prepared by using a magnetic-based stirring device at a temperature of $50{ }^{\circ} \mathrm{C}$. The stirring was performed during $4 \mathrm{~h}$, which ensured homogenic mixtures. The mixtures were then monitored for 2 days in normal room conditions to verify there is no precipitation occurring, which confirmed the mixtures were stable. The second method to verify the stability of the mixtures was ATR-FTIR spectra, which were measured for all the mixtures. If the intensity and position of the characteristic peaks did not change after two days we considered the mixtures to be stable [30-34]. However, it turned out that all the mixtures we used were stable. Prior to the tribological tests, we put the oils on a magnetic stirrer for another hour at $50{ }^{\circ} \mathrm{C}$ to further ensure the homogeneity of all the mixtures during the tests.

The kinematic viscosity of the mixtures was determined at $40{ }^{\circ} \mathrm{C}$, as well as at $100{ }^{\circ} \mathrm{C}$ and since the values at both temperatures differed by less than $1 \%$ compared to the PAO oils without additives, the kinematic viscosity of both PAO base oils (Table 2) was assumed for all the tested mixtures.

\subsection{Tribological tests}

The tribotests were performed using a MTM tribology tester (MTM2, PCS Instruments, London, UK) using a ball-on-disc configuration. The tested contacts were 
steel/steel under lubrication conditions with base oils and with the mixtures of the same base oils with selected additives (Fig. 1) at 25 and $100{ }^{\circ} \mathrm{C}$. To achieve the same viscosity at both temperatures, PAO 6 and PAO 65 oils were used (Table 2). Before the tribological tests started the steel discs and balls were cleaned with n-heptane and were dried in stream of air. All the oils were placed in the same amount of $10 \mathrm{~mL}$ into the MTM cup, heated to the required temperatures of 25 and $100{ }^{\circ} \mathrm{C}$ and stabilised for $20 \mathrm{~min}$ at the required temperature, with no other treatment. After the temperature stabilised, the test was run according to the same procedure, described later on. All the tests were repeated at least three times. The normal load was $35 \mathrm{~N}$, which results in $1 \mathrm{GPa}$ of contact pressure. Slide-to-roll ratio SRR (corresponds to ratio of sliding vs. entrainment speed) of $50 \%$ was set in all tests. The mean contact velocities (the entrainment velocities, $u_{\mathrm{e}}$ ) ensured the complete separation of the contact surfaces with full-film EHD lubrication conditions. The test were run from high entrainment speed $(2.5 \mathrm{~m} / \mathrm{s})$ toward lower entrainment speed $(1.0 \mathrm{~m} / \mathrm{s})$ in discrete steps of $0.1 \mathrm{~m} / \mathrm{s}$. Each step lasted for 10 $\mathrm{s}$ so that the friction value became stabilised. From the Tallian parameter $\lambda$, calculated according to Eq. (1), the values were above 5 at all contact conditions, for both PAO 6 and PAO 65 oils, confirming that results were obtained in EHD lubrication regime. Moreover, this was clear from uniform friction data and checks of the surfaces after the tribotests.

$$
\lambda=\frac{h_{0}}{\sqrt{R_{q, \text { ball }}^{2}+R_{q, \text { disc }}^{2}}}
$$

The $R_{q}$ roughnesses of samples used in Eq. (1) are given in Table 1, while Hamrock-Dowson equation (Eq. (2), [35]) was used to calculate the minimum film thickness $\left(h_{0}\right)$.

$$
\frac{h_{0}}{R^{\prime}}=3.63\left(\frac{u_{\mathrm{e}} \eta_{0}}{E^{\prime} R^{\prime}}\right)^{0.68}\left(\alpha E^{\prime}\right)^{0.49}\left(\frac{W}{E^{\prime} R^{\prime 2}}\right)^{-0.073}\left(1-\mathrm{e}^{-0.68 k}\right)
$$

\subsection{ATR-FTIR spectroscopy}

ATR-FTIR was employed to determine the chemical characteristics of the steel disc surfaces with the adsorbed films that formed during the tribotests. After every test at both 25 and $100{ }^{\circ} \mathrm{C}$, the disc samples were cleaned. N-heptane was used to rinse the samples, and then were dried with an air stream. Samples were analysed with a FTIR spectrometer (Perkin Elmer, USA), equipped with a diamond ATR high-performance accessory (Harrick Scientific Products Inc., USA). Spectra were recorded at an incidence angle of $45^{\circ}$. The sampling area was set for $0.5 \mathrm{~mm} .4,000-400 \mathrm{~cm}^{-1}$ was selected as the active sampling range. $2,500-1,800 \mathrm{~cm}^{-1}$ region was, however, omitted from the results spectra because of the noise from the diamond crystal. 64 scans were used to obtain the spectra and the measurement resolution was $4 \mathrm{~cm}^{-1}$. A background was also taken before every measurement with a clean ATR crystal that was cleaned with alcohol (isopropyl) and carefully dried using a cellulose cotton. Firm contact between the sample and the crystal was always ensured.

\section{Results}

\subsection{Coefficient of friction (COF) at $25{ }^{\circ} \mathrm{C}$}

The results of the tribological tests for the base oil and the base oil with additives with (1) one and two $\mathrm{COOH}$ groups; (2) variation of chain lengths; (3) variation of polarities; and (4) different saturations for the tests at $25{ }^{\circ} \mathrm{C}$ are presented in Fig. 2. Increased entrainment speed causes the COF to decrease, which is due to thermal shear thinning and has been already explained in several previous studies for similar tests $[4-7,36]$. The highest friction was observed with the base oil without additives, the exception being mixtures with two polar head groups (11C-/ $2 x \mathrm{COOH}$ and $16 \mathrm{C}-/ 2 x \mathrm{COOH})$, which leads to the general observation that the additives decrease the EHD friction. The friction decrease is affected by the additive's molecular structure since the different additives reduce the COF to different extents, i.e., from $3.6 \%$ to $12.4 \%$, which is schematically summarised in Fig. 4.

The additives having just one $\mathrm{COOH}$ group result in an up to $9.7 \%$ lower friction than the additives having two $\mathrm{COOH}$ groups (Fig. 2(a)). As shown in Fig. 4, additives that have only one $\mathrm{COOH}$ group give lower $\mathrm{COF}$ than that the base 


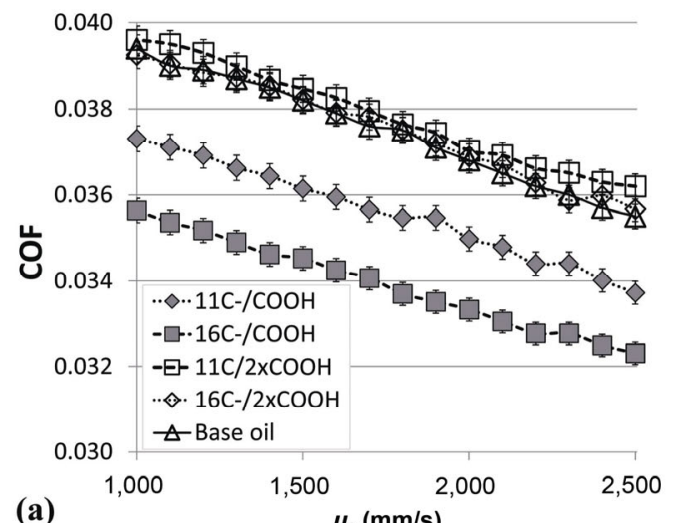

(a)
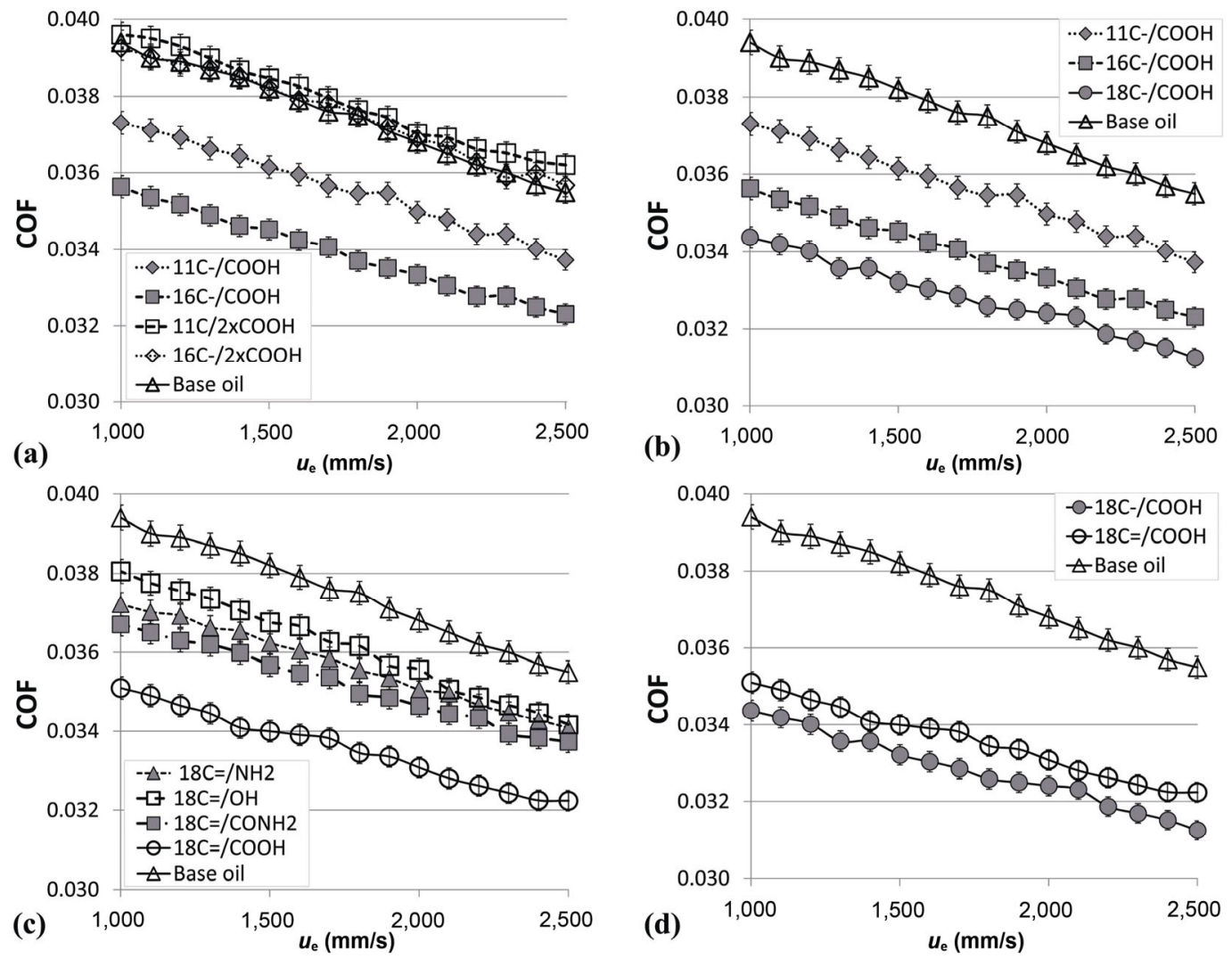

Fig. 2 EHD friction at $25{ }^{\circ} \mathrm{C}$ depending on additive variation of the (a) number of $\mathrm{COOH}$ groups; (b) alkyl chain length; (c) functional groups polarity; and (d) saturation.

oil, while the additives that have two $\mathrm{COOH}$ groups give slightly higher COF (up to 1\%) than the base oil.

When the chain length of the saturated additive with one $\mathrm{COOH}$ group is increased from 11 to $16 \mathrm{C}$, the friction is reduced up to $4.5 \%$. Increase in chain length from 16 to $18 \mathrm{C}$-atoms gives an up to $2.9 \%$ lower friction. Thus the effect of the increasing chain length was the COF reduction by up to $7.4 \%$ (Fig. 1(b)). However, the total reduction in friction for the $18 \mathrm{C}$ molecule with one $\mathrm{COOH}$ group in comparison to the base oil without additives was $12.4 \%$, as seen in Fig. 2(b). On the other hand, the chain length increase for additives with two $\mathrm{COOH}$ groups decreases the $\mathrm{COF}$ only slightly, i.e., by up to $0.8 \%$ (Fig. 2(a)).

The polarity of the additive functional groups reduces the COF (Fig. 2(c)), however, this decrease is not monotonic for fatty alcohol, which is discussed later on. The most polar additive, i.e., fatty acid gives up to $4.3 \%$ lower friction, the fatty amide shows up to $6.8 \%$ lower friction than the fatty alcohol, and up to $5.6 \%$ lower friction than the fatty amine, which is the least-polar additive.

The saturation, which was compared for the additives having $18 \mathrm{C}$-atoms and one $\mathrm{COOH}$ group, decreases the friction by up to $2 \%$ (Fig. 2(d)). The saturated fatty acid with the longest chain length (18C) gives the lowest COF among all the selected additives and reduces the friction by up to $12.4 \%$ in comparison to the oil without additives (Fig. 4).

\section{$3.2 \mathrm{COF}$ at $100{ }^{\circ} \mathrm{C}$}

The results of the tribological tests for the base oil and the base oil with additives with (1) one and two $\mathrm{COOH}$ groups; (2) variation of chain lengths; (3) variation of polarities; and (4) different saturations at $100{ }^{\circ} \mathrm{C}$ are shown in Fig. 3. Compared to the $25{ }^{\circ} \mathrm{C}$ tests, the COF does not decrease with the increasing entrainment velocity since the thermal effect is diminished by the external temperature, confirming the earlier suggestion and previous reports [4-7, 36], while newly introduced oleophobic surface behaviour may also contribute to overall friction behaviour. The highest friction is always measured 
for the base oil without additives, which is slightly different from the case at $25{ }^{\circ} \mathrm{C}$, where mixtures with two polar head groups provided slightly higher friction. However, we can again confirm that the additive molecular structure affects the

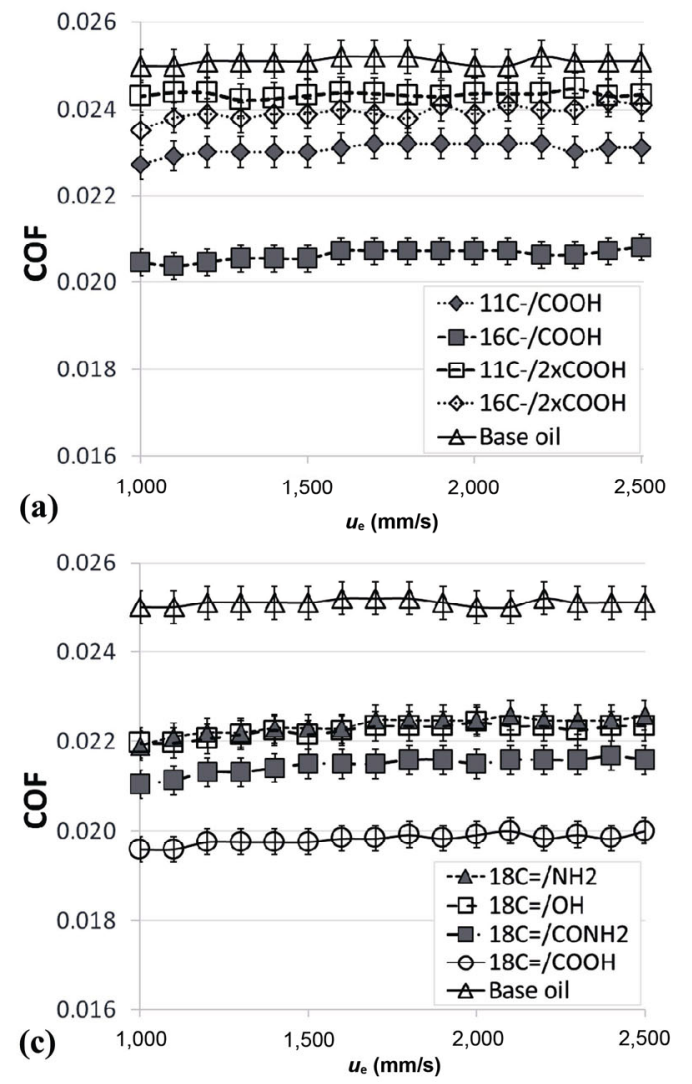

friction noticeably, and differently for various additive chemical structures, i.e., from $3.0 \%$ to $22.2 \%$. This is a significantly higher effect of additives and their molecular configuration on friction than at $25{ }^{\circ} \mathrm{C}$, which is presented in Fig. 4.
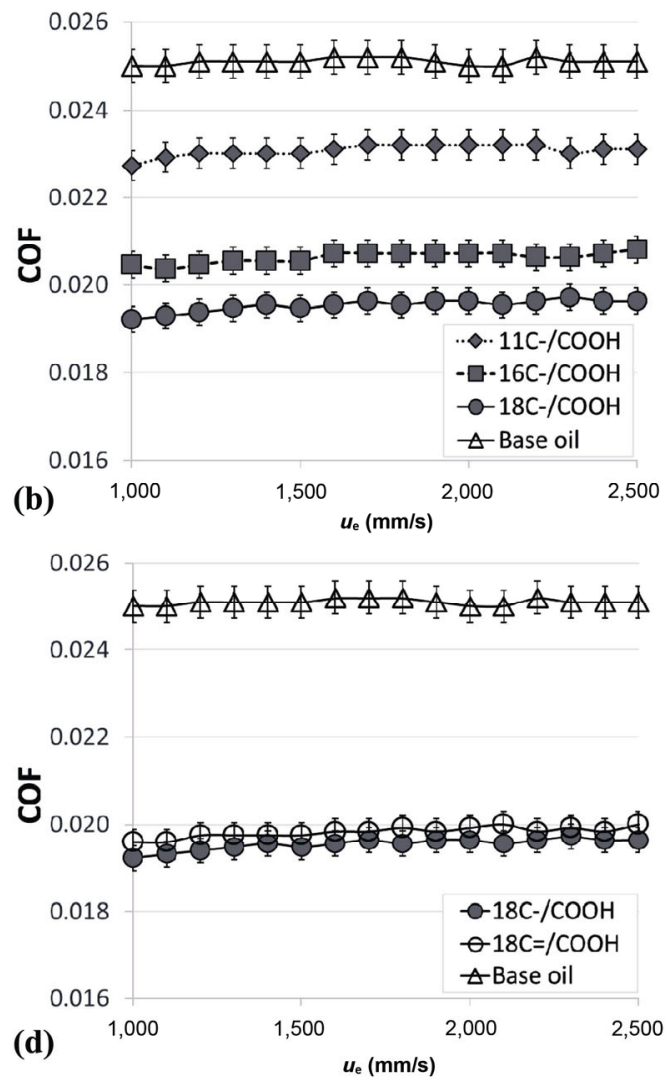

Fig. 3 EHD friction at $100{ }^{\circ} \mathrm{C}$ depending on additive variation of the (a) number of $\mathrm{COOH}$ groups; (b) alkyl chain length; (c) functional groups polarity; and (d) saturation.

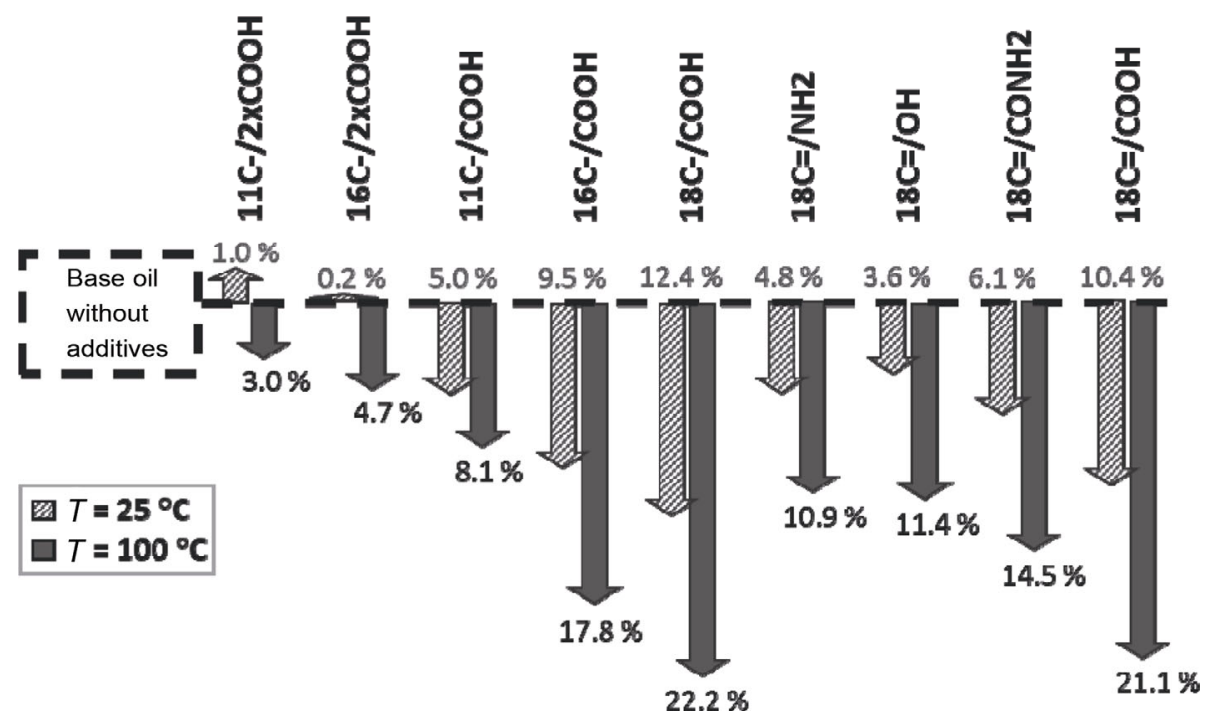

Fig. 4 Average difference in the COF (in \%) between the base oil with additive and the base oil without additives. 
From Fig. 3(a), we see that for the same number of $\mathrm{C}$ atoms, the additives that have only one $\mathrm{COOH}$ group result in up to $20.0 \%$ lower friction than the additives, which have two $\mathrm{COOH}$ groups. Longer chain lengths provide even lower friction, with both one and two polar groups. The one $\mathrm{COOH}$ group molecule with 16C atoms gives a noticeably lower friction than all the others, resulting in an up to $17.8 \%$ lower COF in comparison to the base oil (Fig. 3(a)). This is a slightly greater friction reduction than at $25{ }^{\circ} \mathrm{C}$. While at $25{ }^{\circ} \mathrm{C}$ the additives with two $\mathrm{COOH}$ groups slightly increase the friction, at $100{ }^{\circ} \mathrm{C}$ they decrease it, like the other additives.

Increase of the alkyl chain of the saturated additive with one $\mathrm{COOH}$ group from 11 to $16 \mathrm{C}$ give an up to $10.7 \%$ lower friction, while the increase from 16 to $18 \mathrm{C}$ give an up to $4.7 \%$ lower friction, and thus the effect of chain length was a COF decrease of up to $15.4 \%$ (Fig. 3(b)). However, the total reduction in friction for the $18 \mathrm{C}$ molecule with one $\mathrm{COOH}$ group in comparison to the base oil without additives was $22.2 \%$ (Fig. 2(b)). Increase of the alkyl chain for additives having two $\mathrm{COOH}$ groups decreases the COF only slightly, i.e., up to $1.8 \%$ (Fig. 2(a)).

The higher polarity of the additive functional groups reduces the COF (Fig. 2(c)). In contrast to $25{ }^{\circ} \mathrm{C}$, the friction decrease is in accordance with the polar nature of the polar heads, namely from the lowest polarity amine $\left(\mathrm{NH}_{2}\right)$ to alcohol $(\mathrm{OH})$, amide $\left(\mathrm{CONH}_{2}\right)$ and finally to highest polarity carboxylic acid $(\mathrm{COOH})$. Indeed, alcohol and amine have almost the same values $(10.9 \%$ and $11.4 \%$ less than the base oil), but the general effect of polarity is still maintained. However, it is very clear and significant that the amide has a $14.5 \%$ lower friction than the base oil and $3.0 \%-3.6 \%$ compared to the alcohol and amine, while carboxylic acid, which is the most polar, provided an up $8.1 \%$ lower friction than the amide, $10.9 \%$ lower than the alcohol and amine, and even $11.4 \%$ lower than the base oil. This friction reduction is thus clearly more significant at $100{ }^{\circ} \mathrm{C}$ than at $25{ }^{\circ} \mathrm{C}$.

The saturation, which was compared for the additives having $18 \mathrm{C}$-atoms and one $\mathrm{COOH}$ group, decreases the friction by up to $1.4 \%$. The saturated fatty acid with the longest alkyl chain of $18 \mathrm{C}$ atoms gives the lowest COF among all the tested additives and reduces the friction by up to $22.2 \%$ in comparison to the base oil without additives, as seen in Fig. 4. This is the same as for $25{ }^{\circ} \mathrm{C}$, however, at $100{ }^{\circ} \mathrm{C}$ also the unsaturated long-chain (18C) fatty acid provides a similarly low friction, i.e., $21.1 \%$ lower than it was measured with the base oil.

\subsection{ATR-FTIR results at 25 and $100{ }^{\circ} \mathrm{C}$}

The ATR-FTIR spectra of the discs' surfaces after the tribological tests with the base oil and the base oil with the additives at $25{ }^{\circ} \mathrm{C}$ is presented in Fig. 5 , while the spectra obtained at $100{ }^{\circ} \mathrm{C}$ is presented in Fig. 6. The absorbance peaks intensity in each spectrum is written next to every characteristic peak.

After the tribological tests at both temperatures, the ATR-FTIR spectra show characteristic peaks that correspond to the tested additives' molecular structures. However, comparing the spectra after the tests at 25 and $100{ }^{\circ} \mathrm{C}$ (Figs. 5 and 6), it is obvious that the peaks' intensities are significantly higher at high temperature $(\sim 0,25$ a.u.) than at room temperature ( $\sim, 12$ a.u.). This indicates more intensive adsorption of additives at $100{ }^{\circ} \mathrm{C}$ than at $25{ }^{\circ} \mathrm{C}$, which agrees with the earlier reports in Refs. [23, 26, 37].

For the additives that have two $\mathrm{COOH}$ groups, the characteristic peaks are observed in the ranges $1,420-1,190$ and $945-880 \mathrm{~cm}^{-1}$, which are typical for dicarbonyl vibrations (HOOC-R-COOH) [38], as shown in Figs. 5(a) and 6(a). It can be noticed that longer chain $16 \mathrm{C}-/ 2 x \mathrm{COOH}$ has higher intensity of these peaks than $11 \mathrm{C}-/ 2 x \mathrm{COOH}$, which is true for both 25 and $100{ }^{\circ} \mathrm{C}$ (Figs. 5(a) and 6(a)). In the case of the additives with one $\mathrm{COOH}$ group, these peaks are not measured. However, we observe the bands at $\sim 2,920$ and $\sim 2,855 \mathrm{~cm}^{-1}$ for additives that contain one as well as two $\mathrm{COOH}$ groups, and these bands correspond to the stretching and bending of the $\mathrm{C}-\mathrm{C} \mathrm{sp} \mathrm{p}^{3}$ hybridisation (methylene $(v$ $\mathrm{CH}_{2}$ ) group) [38-40]. It is also noted that for additives with one $\mathrm{COOH}$ group the intensity of these bands is o stronger than for two $\mathrm{COOH}$ groups. This is true for both temperatures, while these peaks are more pronounced at $100{ }^{\circ} \mathrm{C}$ (Fig. 6(a)) than at $25{ }^{\circ} \mathrm{C}$ (Fig. 5(a)). The bands found at $\sim 1,700$ and $\sim 1,460 \mathrm{~cm}^{-1}$ measured in both spectra, namely at 25 and $100{ }^{\circ} \mathrm{C}$, correspond to the vibrations mode of 
the ( $v \mathrm{C}=\mathrm{O})$ bonds [41].

For the additives with different chain lengths (Figs. 5(b) and 6(b)), we observe the same characteristic peaks at $\sim 2,920$ and $\sim 2,855 \mathrm{~cm}^{-1}\left(\vee \mathrm{CH}_{2}\right) ; \sim 1,700$ and $\sim 1,460 \mathrm{~cm}^{-1} \quad(v \quad \mathrm{C}=\mathrm{O}) ; \sim 725 \mathrm{~cm}^{-1} \quad\left(-\left(\mathrm{CH}_{2}\right)_{\mathrm{n}}-\right) \quad$ [38]; however, they decrease with the decreasing chain length of the additive at both 25 and $100{ }^{\circ} \mathrm{C}$. This suggests the involvement of all these species in the formation of the surface film, but their formation is influenced by the length of the additive [42]. Again, the peaks are far more distinct at $100{ }^{\circ} \mathrm{C}$ (Fig. 6(b)) compared to $25{ }^{\circ} \mathrm{C}$ (Fig. 5(b)), indicating temperature dependent formation of the additive film [26].

The spectra of the discs after the tribotests at 25 and $100{ }^{\circ} \mathrm{C}$ with additives having different polarity of the head group, show characteristic peaks [38,
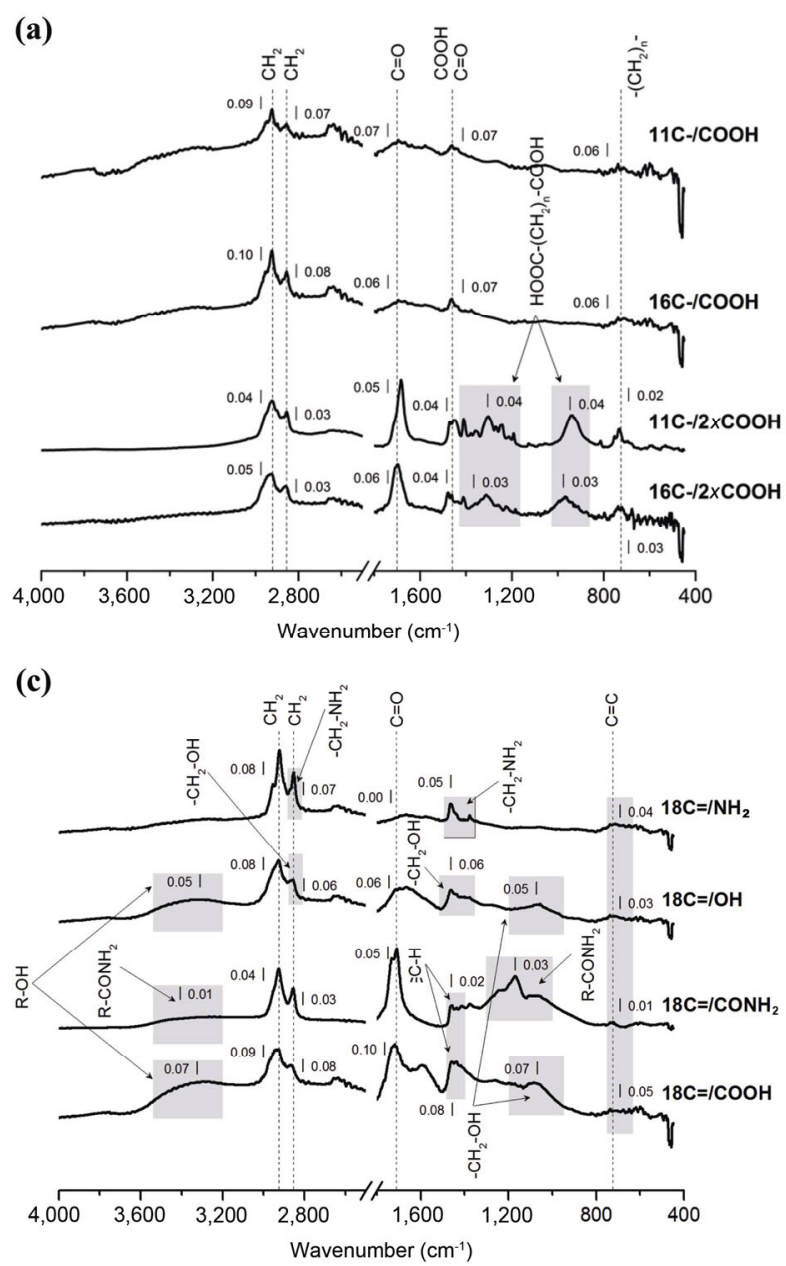

43], which are attributed to alcohols $\left(3,500-3,200 \mathrm{~cm}^{-1}\right.$, $\left.\sim 1,470-1,365 \mathrm{~cm}^{-1}, \sim 1,265-1,140 \mathrm{~cm}^{-1},-\mathrm{CH}_{2}-\mathrm{OH}\right)$; alcohols $\left(3,500-3,200 \mathrm{~cm}^{-1}, \sim 1,470-1,365 \mathrm{~cm}^{-1}, \sim 1,265-1,140 \mathrm{~cm}^{-1}\right.$, $\left.-\mathrm{CH}_{2}-\mathrm{OH}\right)$; amines $\left(\sim 2,855 \mathrm{~cm}^{-1}, \sim 1,470-1,365 \mathrm{~cm}^{-1}\right.$, $\left.-\mathrm{CH}_{2}-\mathrm{NH}_{2}\right)$; and amides $\left(\sim 3,500-3,200 \mathrm{~cm}^{-1}, \sim 1,300\right.$ $\left.1,000 \mathrm{~cm}^{-1},-\mathrm{CH}_{2}-\mathrm{CO}-\mathrm{NH}_{2}\right)$. The peaks between 750 and $630 \mathrm{~cm}^{-1}$ correspond to the $(v \mathrm{C}=\mathrm{C})$ stretching, which is present due to the unsaturated molecular structure of the additives (Figs. 5(c) and 6(c), and Table 2).

The spectra of the additives with different saturations (Figs. 5(d) and 6(d)) show higher intensities of the characteristic peaks for the saturated $18 \mathrm{C}-1$ $\mathrm{COOH}$ than the unsaturated $18 \mathrm{C}=/ \mathrm{COOH}$ additive at both 25 and $100{ }^{\circ} \mathrm{C}$. The spectrum of the disc recorded after the tribotest using base oil without additives at $25{ }^{\circ} \mathrm{C}$ (Fig. 5(d)) and $100{ }^{\circ} \mathrm{C}$ (Fig. 6(d))
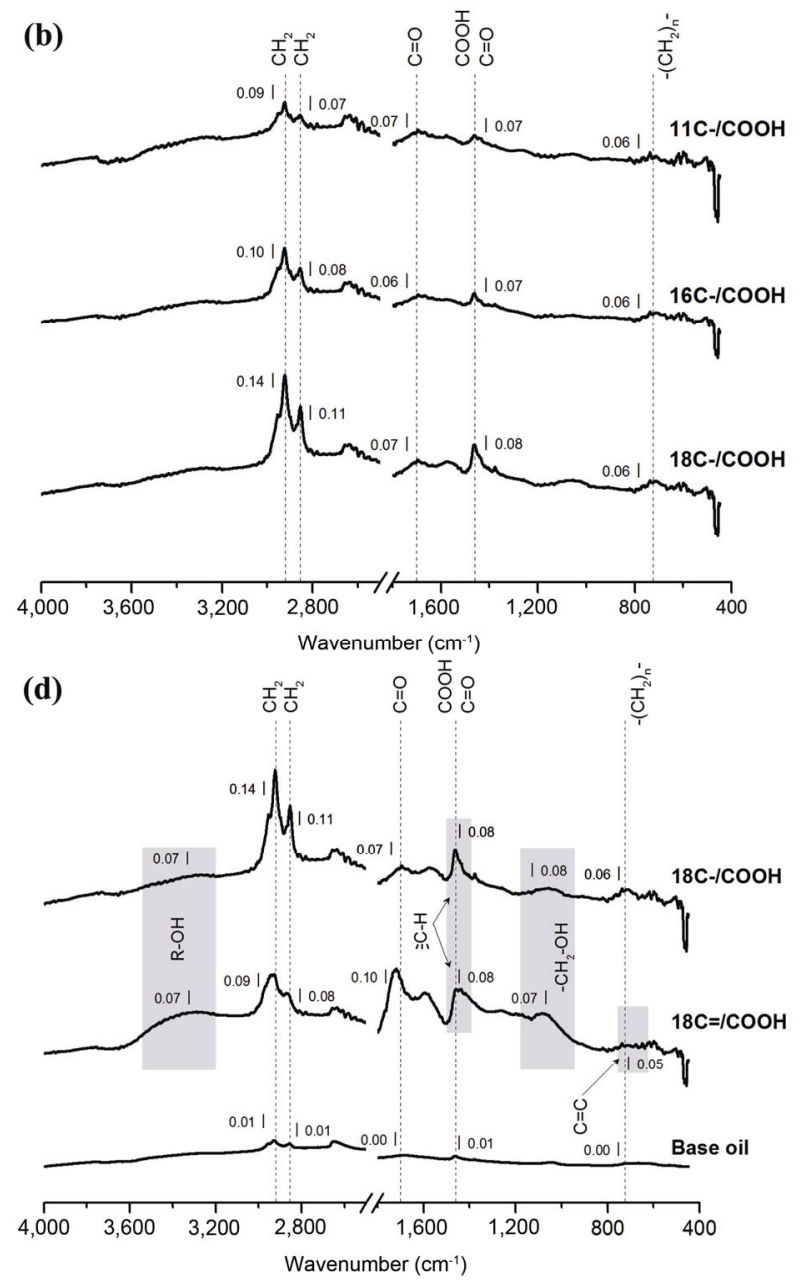

Fig. 5 ATR-FTIR spectra of steel discs after tribological tests at $25{ }^{\circ} \mathrm{C}$ with base oil and a mixture of base oil and additives having different (a) numbers of $\mathrm{COOH}$ groups; (b) chain lengths; (c) polarities of the functional groups; and (d) saturations. 

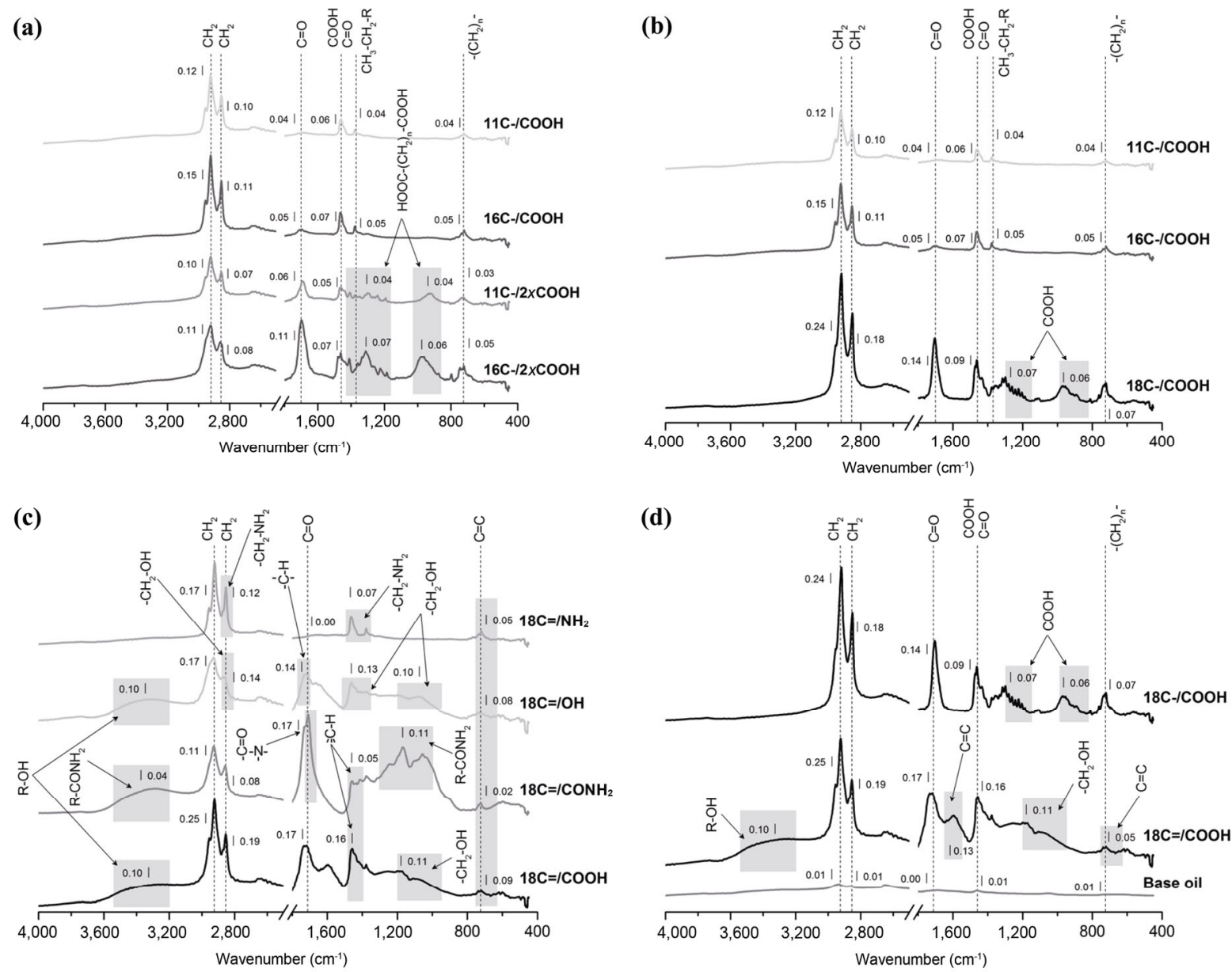

Fig. 6 ATR-FTIR spectra of steel discs after tribological tests at $100{ }^{\circ} \mathrm{C}$ with base oil and base oil with additives having different (a) numbers of $\mathrm{COOH}$ groups; (b) chain lengths; (c) polarities of functional groups; and (d) saturations.

shows only three low-intensity peaks ( $\sim 0.01$ a.u.) that belong to the $\left(\mathrm{vCH}_{2}\right)$ stretching.

\section{Discussion}

It is already well known and documented that when in solid-liquid interactions, the hydro/oleophobicity increases, while the friction drag and energy consumption are reduced. This was shown in many nano-scale studies [12-15] and even in low-load contacts in the range of a few $\mathrm{MPa}[8,19$, 20]. However, in recent years several studies have confirmed that achieving oleophobicity with poor wetting in oil-lubricated contacts also significantly changes the friction behaviour in full-film EHD lubrication in the GPa range [6, 7]. Our earlier studies confirmed this by using various DLC coatings with a tailored surface energy $[10,11]$.
Moreover, it was shown that successful wetting management is possible through the spreading parameter $[6,10,11]$, which gives more insight into the oil adsorption and dynamic wetting properties. This is in contrast to the most commonly used static contact angle, which, however, in cases of spreading wetting behaviour that is typical for most oils on engineering surfaces, does not provide the relevant information [11, 21, 22].

In this view, it would be extremely beneficial if the poor wetting in the EHL regime could be achieved with a simpler technology, where existing metal surfaces (typically steel) could be used directly, without the need for expensive and complex coating depositions. The formation of permanent oleophobic surface layers in the EHL contacts in-situ, which would provide the poor wetting behaviour at the solid-liquid interface, is thus an ambitious but 
rewarding new technology to reduce the friction in EHL steel contacts.

In fact, our recent studies have shown that as a proof of concept for wetting, tailoring can be achieved even with simple organic additives, such as fatty acids, alcohols, amines, and amides with various molecular architectures [21, 22]. The variation of wetting by employing these simple oiliness additives was confirmed both at room temperature and elevated temperature of $100{ }^{\circ} \mathrm{C}$, where the wetting dynamic contact angles, as well as contact angle hysteresis (CAH) changed dramatically, by several times. In the current research we have used exactly the same base oils, the same additives and the same metal surfaces as in the wetting studies [21, 22]. This is purposely done to use the evidence of wetting behaviour from wetting studies that are already well documented and described in detail in above mentioned available literature.

In this study, therefore, we used the same additives as in previous wetting studies to investigate whether this concept, i.e., poor wetting and consequent boundary slip, is a valid way to reduce the EHL friction, and how sensitive the EHL friction is to relatively small variations in the additives' molecular structures. However, to confirm the effect of additives on friction, their adsorbed layers at the tribologicallytested surfaces has to be proved, for which the ATR-FTIR analyses were perfomed in this work (Figs. 5 and 6).

Moreover, in previous studies using DLC to reduce the EHL friction, a complementary plausible mechanism was proposed due to the coating's thermal isolation properties and the consequently increased contact temperature that reduces the viscosity and so the friction. However, in this study we completely excluded any possible thermal effect in the contacts, since the study is performed using steel/steel contacts and the nm-thick adsorbed additive layers only, which can thus confirm or ruleout the thermal EHD friction-reduction mechanism. It is well known that the nm-thickness molecular layer cannot provide any relevant isolation, as well as the negligible variations in the physical properties [26] between selected molecules cannot make any distinction in this respect.

The results in this study show that all the selected additive mixtures successfully adsorbed to the steel surfaces, without any additional treatment or procedures, simply via the adsorption of the polar heads to the metal surfaces [23, 26]. The ATR-FTIR spectra indicate the adsorption of organic species on the steel discs during the tribotests for all the mixtures of additives with oil, both at 25 and $100{ }^{\circ} \mathrm{C}$, while for the base oil without additives it does not, as shown in Figs. 5 and 6. The presence of adsorbed species at $25{ }^{\circ} \mathrm{C}$ might seem unexpected, however, this was most probably due to a local temperature increase, clearly seen from thermal oil thinning and friction reduction in our friction tests (see the strong decrease of friction in Fig. 2), as well as due to possible pressure-induced tribomechanical interactions [26, 44-49]. Moreover, comparing Figs. 5 and 6 , the adsorption at $25{ }^{\circ} \mathrm{C}$ is clearly much weaker than at $100{ }^{\circ} \mathrm{C}$, supporting the overall lower tribochemical activity. Therefore, in the test at $25{ }^{\circ} \mathrm{C}$ it was mostly physical adsorption that occurred, but partially the additive film was formed also through the chemisorption, as confirmed by the ATR-FTIR results (Fig. 5), which is relatively mild binding, but well known to be effective in tribological contacts under even much more severe conditions, such as the mixed and boundary regimes [26]. In contrast, at $100{ }^{\circ} \mathrm{C}$ the chemical adsorption occurred in all cases (Fig. 6), which provides much stronger bonding of the adsorbed layer.

In agreement with the fact that additives selected for this study provide substantial oleophobic wetting behaviour [21, 22], and the chemical evidence of the adsorbed films on the surfaces after the tribotests (Figs. 5 and 6), the hypothesis of this study that EHL friction is affected by the films of oiliness additives was verified. The friction decreased by $3.6 \%-12.4 \%$ at $25{ }^{\circ} \mathrm{C}$ and by $3.0 \%-22.2 \%$ at $100{ }^{\circ} \mathrm{C}$. This is a very significant reduction in the friction, especially for $100{ }^{\circ} \mathrm{C}$. Furthermore, this shows that the more strongly chemisorbed film at $100{ }^{\circ} \mathrm{C}$ (Fig. 6) provides lower friction, which is a consequence of the more completely adsorbed film, promoting higher oleophobicity and so more non-polar interactions of the additive alkyl tails and the non-polar PAO oil, which means an easier flow of oil or slip over the adsorbed layer compared to steel surface with typical oil-steel boundary interaction interface. 
This mechanism is schematically shown in Fig. 7.

Moreover, the molecular structure also clearly affected the friction, suggesting the high sensitivity of the EHD friction to relatively small, but consistent, additive changes. The general effect of the molecular structure was the same at 25 and $100{ }^{\circ} \mathrm{C}$. That is to say, the qualitative effect of chain length, polarity, and saturation was the same-an increase of these three additive properties resulted in higher oleophobicity and lower friction. Only the additives with two $\mathrm{COOH}$ groups at $25{ }^{\circ} \mathrm{C}$ resulted in slightly higher friction in comparison to the base oil, which is in the contrary to all the other results. However, at $100{ }^{\circ} \mathrm{C}$ the additives having two $\mathrm{COOH}$ heads, and all the additives having just one $\mathrm{COOH}$ head always exhibited a lower friction than the base oil. The overall difference between the different types of additives (i.e., the different molecular structure) was by $2.9 \%-7.4 \%$ at $25{ }^{\circ} \mathrm{C}$ and by $1.8 \%-20.0 \%$ at $100{ }^{\circ} \mathrm{C}$. So, again, this confirms the stronger effect on the friction by the additives at the higher temperature.

All the additives reduced the COF, with the minor exception described above. It has been suggested that the reduction of friction in full-film $\mathrm{HD}$ conditions at low contact pressures of $\mathrm{MPa}$ range could be caused by organic friction modifiers that can promote fluid slip [8, 50,51]. It has been further argued that due to organic friction modifiers adsorption, the methyl $-\mathrm{CH}_{3}$ groups form planes, which result in smooth and poorly wetted surfaces,

(a)

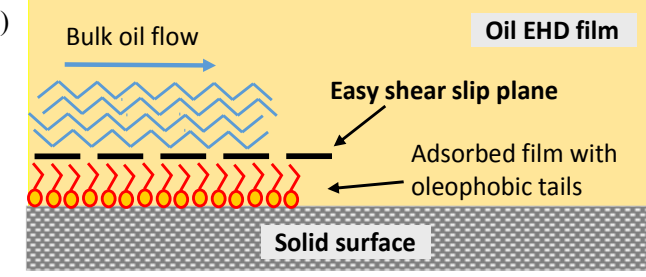

(b)

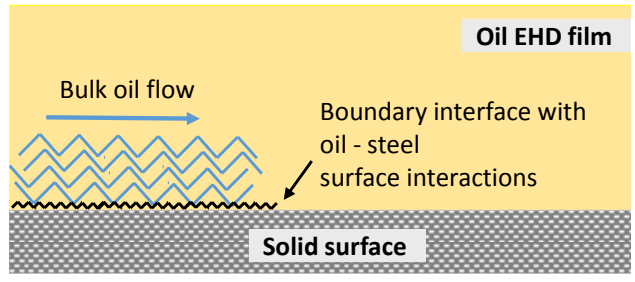

Fig. 7 Schematic presentation of the mechanism for (a) easy shear slip plane between the oleophobic alkyl chain tails and bulk oil film, compared to (b) direct interaction between the oil and the steel surface (commonly oxidised, with contaminants), absent of easy-shear plane. so that liquid can easily slip over such surfaces [8, 26]. Moreover, organic friction modifiers are known to form surface layers that are in nature oleophobic, which thus result in poor wetting by the alkanes [52]. We have reported in our companion studies that the structure of additive molecule significantly influences the wetting of oil on steel at both 25 and $100{ }^{\circ} \mathrm{C}[21,22]$. The slightly higher friction for molecules that have two $\mathrm{COOH}$ groups at $25{ }^{\circ} \mathrm{C}$ (Figs. 2(a) and 3) can be explained by the way that bifunctional acids can adsorb to the steel via one or both $\mathrm{COOH}$ polar heads [53], or react with some other molecule, and so preventing the formation of a packed and dense film with methyl tails on top [54]. In this case the free $\mathrm{COOH}$ groups that may be present at the surface can thus enhance the interactions with the oil in surrounding [54]. This agrees with our ATR-FTIR results (Fig. 4(a)), which clearly show peaks that correspond to dicarbonyl vibrations that are not measured for additives that have only one $\mathrm{COOH}$ polar head.

Numerous studies have shown that fatty acids in oil reduce the friction in boundary lubrication [1, $23,37]$ and that this reduction is dependent on their chain length $[26,55]$, but the influence of the fatty acid's chain length in EHD lubrication, shown in this study (Figs. 2(b) and 3), has not yet been reported. However, it was reported earlier that fatty acids with longer alkyl chains are more stable and stronger and thus form more protective adsorbed films [1, 28, 55]. This agrees with our ATR-FTIR measurements (Fig. 4(b)), which show a higher intensity of the peaks that correspond to the $v \mathrm{CH}_{2}$ group for additives with a longer alkyl chain. We have furthermore presented earlier that the surface becomes more oleophobic when additives with longer alkyl chains are used [21, 22], which is in agreement with the suggestion that fluid slip could cause a reduction of the EHD and HD friction [6-8, 50, 51].

More polar additive head groups decrease the EHD friction, which is true for all the tested additives, except the fatty alcohol at $25{ }^{\circ} \mathrm{C}$ (Figs. 2(c) and 3), however, the difference compared to the fatty amine is within $1.2 \%$, and thus almost negligible. The reason for the polarity effect on the steel surface is that the more polar functional groups of the additive 
result in a more firmly adsorbed film [23, 26, 37, 56]. It is well established that the better the organic friction modifier's adsorption, the more effective its friction-reduction properties will be in boundary lubrication conditions [1, 23, 26, 57]. The effect of the head group's polarity on the friction for ferrous substrates has been extensively investigated [26] and the studies have shown that amine groups as well as carboxylic acid have stronger effects than nitrile, halide or alcohol groups [26, 37, 58, 59]. Recently, we have shown that the oleophobicity increases as the polarity of the additive head increases [21], and the ATR-FTIR spectra (Fig. 4(c)) show a stronger intensity of the organic species when polarity of the additive increases. Stronger additive head adsorption therefore results in a more complete layer of the opposite tails, namely the methylene groups [26], and this can thus cause a larger reduction in the EHD friction.

Finally, the saturation of the additive having the same alkyl chain length and $\mathrm{COOH}$ group decreases the EHD friction (Figs. 2(d) and 3) as well. This result is again in agreement with earlier evidence that saturated fatty acids that possess long and straight alkyl chains, can form very uniform films with alkyl tails oriented perpendicularly to the steel surface $[1,23,56]$. Furthermore, unsaturated fatty acid molecules rotate around the double $\mathrm{C}=\mathrm{C}$ bond, which prevents the formation of a uniform film and complete surface coverage [53, 60, 61]. Our ATR-FTIR spectra (Fig. 4(d)) indeed show the characteristic peaks of $(v \mathrm{C}=\mathrm{C})$ bonds for unsaturated fatty acid and their absence for a saturated acid. Moreover, the stronger intensities of the characteristic $\left(v \mathrm{CH}_{2}\right)$ bonds for saturated fatty acid indicates the more oleophobic behaviour, which has also been experimentally shown with dynamic wetting tests in a previous study [21,22].

The chemical analyses of the adsorbed layers therefore strongly support the observed friction behaviour and explain it through the adsorbed film's structural properties affecting the wetting. Both the chemical and the friction results of nm-thick adsorbed layers of simple organic additives on steel/steel contacts in EHL conditions therefore show that wetting and consequent slip, and the ease of bulk oil sliding over these layers, reduces the friction significantly, by as much as $22 \%$ in this study. Moreover, it shows a high sensitivity to molecular structure, and thus the potential for larger modifications of the additives and so tailoring of the friction. The proposed friction-reduction mechanism does not require any additional coating deposition and excludes all the thermal effects. It only applies to EHL through the already well-established additive-adsorption mechanisms by using conventional boundary-lubrication additives or other surface-active compounds providing high oleophobic properties, such as fluorinated compounds, for example. However, even the very simple organic additives used in this work reduced the EHL friction to a similar extent (up to about $20 \%$ ), as obtained with a-C:H: N-doped DLC [6] or even one of F-doped DLC coatings [7] in our previous studies. Therefore, this study seems to give solid grounds to further develop and tailor the adsorption additives to establish this newly proposed EHD lubrication technology, namely to reduce EHL friction via additive-adsorption mechanisms.

\section{Conclusions}

1) A new lubrication technology to reduce EHL friction using additives on the steel surfaces that form oleophobic boundary layers is described. The friction is sensitive to relatively small variations in the additive molecular structures, indicating a strong potential to tailor the additives and their interactions with the surfaces.

2) More strongly bonded layers (via chemisorption) with better organised layers (from long-chain, saturated, and highly polar additives) provide lower wetting and lower EHD friction.

3) A higher contact temperature of $100{ }^{\circ} \mathrm{C}$ promotes the formation of more strongly adsorbed (oleophobic) boundary layers and reduces the EHD friction more than those at $25{ }^{\circ} \mathrm{C}$.

4) Molecular structures of the selected additive clearly affect the EHD friction, i.e., additives with only one $\mathrm{COOH}$ group, a longer alkyl chain length, a higher polarity of the head group, and a fully saturated structure reduce the EHD friction more than the opposite properties.

5) Friction reduction using additives compared to the base oil was $3.6 \%-12.4 \%$ at $25{ }^{\circ} \mathrm{C}$ and $3.0 \%-$ 


\section{$22.2 \%$ at $100{ }^{\circ} \mathrm{C}$.}

6) Wetting-based EHD friction reduction due to oleophobic films was obtained in steel/steel contacts without a surface thermal effect, which was alternatively suggested for friction reduction with DLC coatings with low wetting, which however, also have lower thermal conductivity. Moroever, the most oleophobic films reduced EHD friction for about the same as was previously observed with DLC coatings, i.e., about $20 \%$, however, additives are much simpler and less expensive technology.

7) Variations between the different molecular structures affect the EHD friction by $2.9 \%-7.4 \%$ at $25{ }^{\circ} \mathrm{C}$ and by $1.8 \%-20.0 \%$ at $100{ }^{\circ} \mathrm{C}$. The most effective additive was found to be saturated fatty acid with $18 \mathrm{C}$ atoms.

\section{Acknowledgements}

The authors acknowledge the financial support from the Slovenian Research Agency (Research Core Funding No. P2-0231).

Open Access This article is licensed under a Creati ve Commons Attribution 4.0 International Li-cense, which permits use, sharing, adaptation, distributio $\mathrm{n}$ and reproduction in any medium or for-mat, as 1 ong as you give appropriate credit to the original a uthor(s) and the source, provide a link to the Creat ive Commons licence, and indicate if changes were made.

The images or other third party material in this article are included in the article's Creative Comm ons licence, unless indicated otherwise in a credit 1 ine to the material. If material is not in-cluded in $\mathrm{t}$ he article's Creative Commons licence and your int ended use is not permitted by statutory regulation or exceeds the permitted use, you will need to obt ain permission directly from the copyright holder.

To view a copy of this licence, visit http://creativecommons.org/licenses/by/4.0/.

\section{References}

[1] Stachowiak G W, Batchelor A W. Engineering Tribology. 3rd edn. Oxford (UK): Elsevier Inc., 2005.

[2] Reynolds O. IV. On the theory of lubrication and its application to Mr. Beauchamp Tower's experiments, including an experimental determination of the viscosity of olive oil. Philos Trans Roy Soc Lond 177: 157-234 (1886)

[3] Grubin A N. Fundamentals of the hydrodynamic theory of lubrication of heavily loaded cylindrical surfaces. In Proceedings of the Symposium on Investigation of the Contact of Machine Components, Moscow, 1949: 115-166.

[4] Björling M, Habchi W, Bair S, Larsson R, Marklund P. Friction reduction in elastohydrodynamic contacts by thin-layer thermal insulation. Tribol Lett 53(2): 477-486 (2014)

[5] Evans R D, Cogdell J D, Richter G A, Doll G L. Traction of lubricated rolling contacts between thin-film coatings and steel. Tribol Trans 52(1): 106-113 (2008)

[6] Kalin M, Polajnar M. The effect of wetting and surface energy on the friction and slip in oil-lubricated contacts. Tribol Lett 52(2): 185-194 (2013)

[7] Polajnar M, Kalin M. Effect of the slide-to-roll ratio and the contact kinematics on the elastohydrodynamic friction in diamond-like-carbon contacts with different wetting behaviours. Tribol Lett 60(1): 8 (2015)

[8] Choo J H, Spikes H A, Ratoi M, Glovnea R, Forrest A. Friction reduction in low-load hydrodynamic lubrication with a hydrophobic surface. Tribol Int 40(2): 154-159 (2007)

[9] Guo F, Yang S Y, Ma C, Wong P L. Experimental study on lubrication film thickness under different interface wettabilities. Tribol Lett 54(1): 81-88 (2014)

[10] Kalin M, Polajnar M. The correlation between the surface energy, the contact angle and the spreading parameter, and their relevance for the wetting behaviour of DLC with lubricating oils. Tribol Int 66: 225-233 (2013)

[11] Kalin M, Polajnar M. The wetting of steel, DLC coatings, ceramics and polymers with oils and water: The importance and correlations of surface energy, surface tension, contact angle and spreading. Appl Surf Sci 293: 97-108 (2014)

[12] Hild W, Opitz A, Schaefer J A, Scherge M. The effect of wetting on the microhydrodynamics of surfaces lubricated with water and oil. Wear 254(9): 871-875 (2003)

[13] Choi C H, Ulmanella U, Kim J, Ho C M, Kim C J. Effective slip and friction reduction in nanograted superhydrophobic microchannels. Phys Fluids 18(8): 087105 (2006)

[14] Zhu Y, Granick S. Rate-dependent slip of Newtonian liquid at smooth surfaces. Phys Rev Lett 87(9): 096105 (2001)

[15] Mate C M. Tribology on the Small Scale. Oxford (UK): Oxford Univ. Press, 2008.

[16] Vinogradova O I. Slippage of water over hydrophobic surfaces. Int J Miner Process 56(1-4): 31-60 (1999) 
[17] Vinogradova O I. Drainage of a thin liquid film confined between hydrophobic surfaces. Langmuir 11(6): 22132220 (1995)

[18] Spikes H, Granick S. Equation for slip of simple liquids at smooth solid surfaces. Langmuir 19(12): 5065-5071 (2003)

[19] Jahanmir S, Hunsberger A Z, Heshmat H. Load capacity and durability of H-DLC coated hydrodynamic thrust bearings. J Tribol 133(3): 031301 (2011)

[20] Guo L, Wong P L, Guo F. Correlation of contact angle hysteresis and hydrodynamic lubrication. Tribol Lett 58(3): 45 (2015)

[21] Kus M, Kalin M. Influence of additives and their molecular structure on the static and dynamic wetting of oil on steel at room temperature. Appl Surf Sci 490: 420-429 (2019)

[22] Kus M, Kalin M. Additive chemical structure and its effect on the wetting behaviour of oil at $100{ }^{\circ} \mathrm{C}$. Appl Surf Sci 506: 145020 (2020)

[23] Mortier R M, Fox M F, Orszulik S T. Chemistry and Technology of Lubricants. 3rd edn. New York (USA): Springer, 2010.

[24] Friction Modifier System, Unique Patented Friction Reducing Technology, A. Chemicals, Catalogue 2011.

[25] Leading the way in naturally derived ingredients, Organic Friction Modifiers., Additives C L, Catalogue 2009.

[26] Spikes H. Friction modifier additives. Tribol Lett 60: 5 (2015)

[27] Mohrig J R, Hammond C R, Morrill T C. Experimental Organic Chemistry. New York (USA): Freeman, 1998.

[28] Bowden F P, Tabor D. The Friction and Lubrication of Solids, Part I. Oxford (UK): Clarendon Press, 1950.

[29] Jahanmir S, Beltzer M. An adsorption model for friction in boundary lubrication. ASLE Trans 29(3): 423-430 (1986)

[30] Dunuwila D D, Berglund K A. ATR FTIR spectroscopy for in situ measurement of supersaturation. J Cryst Growth 179(1-2): 185-193 (1997)

[31] Groen H, Roberts K J. Nucleation, growth, and pseudopolymorphic behavior of citric acid as monitored in situ by attenuated total reflection Fourier transform infrared spectroscopy. The J Phys Chem B 105(43): 1072310730 (2001)

[32] Lewiner F, Klein J P, Puel F, Févotte G. On-line ATR FTIR measurement of supersaturation during solution crystallization processes. Calibration and applications on three solute/solvent systems. Chem Eng Sci 56(6): 2069-2084 (2001)

[33] Feng L L, Berglund K A. ATR-FTIR for determining optimal cooling curves for batch crystallization of succinic acid. Cryst Growth Des 2(5): 449-452 (2002)

[34] Bakhbakhi Y, Charpentier P, Rohani S. The solubility of phenanthrene in toluene: In-situ ATR-FTIR, experimental measurement, and thermodynamic modelling. Can J Chem Eng 83(2): 267-273 (2005)

[35] Hamrock B J, Dowson D. Isothermal elastohydrodynamic lubrication of point contacts: Part III-Fully flooded results. J Lubr Technol 99(2): 264-275 (1977)

[36] Lafountain A R, Johnston G J, Spikes H A. The elastohydrodynamic traction of synthetic base oil blends. Tribol Trans 44(4): 648-656 (2001)

[37] Rizvi S Q A. A Comprehensive Review of Lubricant Chemistry, Technology, Selection and Design. ASTM stock number: MNL59, West Conshohocken: ASTM, 2009.

[38] Socrates G. Infrared and Raman Characteristic Group Frequencies: Tables and Charts. New York (USA): Wiley, 2004.

[39] Rossi A, Eglin M, Piras F M, Matsumoto K, Spencer N D. Surface analytical studies of surface-additive interactions, by means of in situ and combinatorial approaches. Wear 256(6): 578-584 (2004)

[40] Piras F M, Rossi A, Spencer N D. Growth of tribological films: In situ characterization based on attenuated total reflection infrared spectroscopy. Langmuir 18(17): 6606-6613 (2002)

[41] Castro W, Perez J M, Erhan S Z, Caputo F. A study of the oxidation and wear properties of vegetable oils: Soybean oil without additives. J Am Oil Chem Soc 83(1): 47-52 (2006)

[42] Kumar S, Mishra N M, Mukherjee P S. Additives depletion and engine oil condition-a case study. Ind Lubr Tribol 57(2): 69-72 (2005)

[43] Duddeck H. E. E. Pretsch, P. Bühlmann, C. Affolter. Structure determination of organic compounds-Tables of spectra data. Springer, Berlin, 2000. 421 pp. plus CD-ROM. Price $£$ 40.39, DM 79.00. ISBN 354067815 8. Magn Reson Chem 40(3): 247-247 (2002)

[44] Gosvami N N, Bares J A, Mangolini F, Konicek A R, Yablon D G, Carpick R W. Mechanisms of antiwear tribofilm growth revealed in situ by single-asperity sliding contacts. Science 348(6230): 102-106 (2015)

[45] Adams H L, Garvey M T, Ramasamy U S, Ye Z J, Martini A, Tysoe W T. Shear-induced mechanochemistry: Pushing molecules around. J Phys Chem C 119(13): 7115-7123 (2015)

[46] Adams H, Miller B P, Kotvis P V, Furlong O J, Martini A, Tysoe W T. In situ measurements of boundary film formation pathways and kinetics: Dimethyl and diethyl disulfide on copper. Tribol Lett 62: 12 (2016)

[47] Felts J R, Oyer A J, Hernández S C, Whitener Jr K E, Robinson J T, Walton S G, Sheehan P E. Direct mechanochemical cleavage of functional groups from graphene. Nat Commun 6: 6467 (2015)

[48] Yeon J, He X, Martini A, Kim S H. Mechanochemistry 
at solid surfaces: Polymerization of adsorbed molecules by mechanical shear at tribological interfaces. ACS Appl Mater Interfaces 9(3): 3142-3148 (2017)

[49] He X, Kim S H. Mechanochemistry of physisorbed molecules at tribological interfaces: Molecular structure dependence of tribochemical polymerization. Langmuir 33(11): 2717-2724 (2017)

[50] Spikes H A. Slip at the wall-evidence and tribological implications. Tribol Ser 41: 525-535 (2003)

[51] Choo J H, Forrest A K, Spikes H A. Influence of organic friction modifier on liquid slip: A new mechanism of organic friction modifier action. Tribol Lett 27(2): 239-244 (2007)

[52] Hare E F, Zisman W A. Autophobic liquids and the properties of their adsorbed films. J Phys Chem 59(4): 335-340 (1955)

[53] Bigelow W C, Pickett D L, Zisman W A. Oleophobic monolayers: I. Films adsorbed from solution in non-polar liquids. J Colloid Sci 1(6): 513-538 (1946)

[54] Tamam L, Ocko B M, Deutsch M. Two-dimensional order in mercury-supported langmuir films of fatty

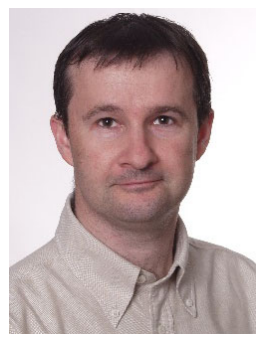

Mitjan KALIN. He received his Ph.D. from Faculty of Mechanical Engineering at University of Ljubljana, Slovenia in 1999. After his post-doc research at National Institute of Standards and Technology (NIST, Gaithersburg, USA), he joined the University of Ljubljana in 2000 as an assistant professor, where he is now full professor, head of

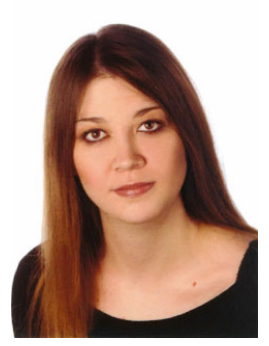

Maja KUS. She received her master in chemical engineering from University of Ljubljana, Slovenia in 2013. She received her Ph.D. in mechanical engineering from University of Ljubljana in 2019. During this time, she was working diacids. Langmuir 28(44): 15586-15597 (2012)

[55] Jahanmir S. Chain length effects in boundary lubrication. Wear 102(4): 331-349 (1985)

[56] Torbacke M, Rudolphi A K, Kassfeldt E. Lubricants: Introduction to Properties and Performance. Chichester (UK): Wiley, 2014.

[57] Spikes H A. Film-forming additives-direct and indirect ways to reduce friction. Lubr Sci 14(2): 147-167 (2002)

[58] Okabe H, Masuko M, Sakurai K. Dynamic behavior of surface-adsorbed molecules under boundary lubrication. ASLE Trans 24(4): 467-473 (1981)

[59] Jahanmir S, Beltzer M. Effect of additive molecular structure on friction coefficient and adsorption. J Tribol 108(1): 109-116 (1986)

[60] Studt P. The influence of the structure of isomeric octadecanols on their adsorption from solution on iron and their lubricating properties. Wear 70(3): 329-334 (1981)

[61] Doig M, Warrens C P, Camp P J. Structure and friction of stearic acid and oleic acid films adsorbed on iron oxide surfaces in squalane. Langmuir 30(1): 186-195 (2014)

the Laboratory for Tribology and Interface Nanotechnology, and head of the Chair for Tribology and Maintenance Technology. Currently he holds a position of a dean of the Faculty of Mechanical Engineering in a four-year term. His research areas cover the wear and friction mechanisms of advanced materials, nanoscale interface phenomena, and boundary films and contact engineering for novel green-lubrication technologies.

as an assistant and researcher in Laboratory for Tribology and Nanotechnology, Faculty of Mechanical Engineering at University of Ljubljana. Currently, she is working at Novartis Technical OperationsLjubljana Solids as part of manufacturing and science team. 